Brewster-angle measurements of sea-surface reflectance using a high resolution spectroradiometer

This article has been downloaded from IOPscience. Please scroll down to see the full text article.

2002 J. Opt. A: Pure Appl. Opt. 4 S29

(http://iopscience.iop.org/1464-4258/4/4/361)

View the table of contents for this issue, or go to the journal homepage for more

Download details:

IP Address: 130.159.17.137

The article was downloaded on 08/07/2010 at 10:29

Please note that terms and conditions apply. 


\title{
Brewster-angle measurements of sea-surface reflectance using a high resolution spectroradiometer
}

\author{
Alex Cunningham, Peter Wood and David McKee \\ Environmental Optics Laboratory, Department of Physics and Applied Physics, University of \\ Strathclyde, Glasgow G4 ONG, UK
}

Received 4 February 2002, in final form 16 May 2002

Published 8 July 2002

Online at stacks.iop.org/JOptA/4/S29

\begin{abstract}
This paper describes the design, construction and testing of a ship-borne spectroradiometer based on an imaging spectrograph and cooled CCD array with a wavelength range of $350-800 \mathrm{~nm}$ and $4 \mathrm{~nm}$ spectral sampling. The instrument had a minimum spectral acquisition time of $0.1 \mathrm{~s}$, but in practice data were collected over periods of $10 \mathrm{~s}$ to allow averaging of wave effects. It was mounted on a ship's superstructure so that it viewed the sea surface from a height of several metres at the Brewster angle $\left(53^{\circ}\right)$ through a linear polarizing filter. Comparison of sea-leaving spectra acquired with the polarizer oriented horizontally and vertically enabled estimation of the spectral composition of sky light reflected directly from the sea surface. A semi-empirical correction procedure was devised for retrieving water-leaving radiance spectra from these measurements while minimizing the influence of reflected sky light. Sea trials indicated that reflectance spectra obtained by this method were consistent with the results of radiance transfer modelling of case 2 waters with similar concentrations of chlorophyll and coloured dissolved organic matter. Surface reflectance signatures measured at three locations containing blooms of different phytoplankton species were easily discriminated and the instrument was sufficiently sensitive to detect solar-stimulated fluorescence from surface chlorophyll concentrations down to $1 \mathrm{mg} \mathrm{m}^{-3}$.
\end{abstract}

Keywords: Spectroradiometry, remote sensing, ocean colour

\section{Introduction}

There is considerable current interest in acquiring high resolution measurements of marine spectral reflectance from close to the sea surface in order to assist the interpretation of data from airborne and satellite radiometers (Bukata 1995). For vicarious instrument calibration or 'sea-truth' provisions, reflectance measurements should be made with a downwards irradiance sensor $\left(E_{d}\right)$ positioned just above the sea surface and an upwelling radiance sensor $\left(L_{u}\right)$ positioned just below the surface, and this usually involves mounting equipment on a buoy or mooring (Mueller and Austin 1995). Measurements of water-leaving radiance $\left(L_{w}\right)$ from above the surface suffer from the contaminating effects of reflected sky light and are very sensitive to changes in the angle of view caused by waves and the motion of the observing platform. If these disadvantages could be overcome, ship-borne radiometers could reveal fine-scale spatial structures that are not resolved in airborne imagery or fixed moorings and provide radiometric data when flights are restricted by cloud cover, aircraft operating range or difficulties of access. Since data can be collected while the ship is underway, the development of effective techniques for measuring ocean colour from above the surface would make efficient use of passage time and allow unattended operation on ships of opportunity. In response to this growing interest, commercial instruments for abovesurface marine spectroradiometry have been produced by Trios Sensors (Germany) and Satlantic (Canada). However, it is possible to construct high resolution ('hyperspectral') marine radiometers with only modest engineering facilities, and this 
allows a more flexible exploration of problems such as viewing angles and strategies for surface reflection compensation. This paper describes the design and preliminary testing of a laboratory-built ship-mounted radiometer which has been successfully deployed in coastal waters (Cunningham et al 2001) and the Atlantic Ocean (Wood and Cunningham 2001).

\section{Methodology}

\subsection{Instrument design}

A number of optical factors have to be considered in determining the choice of components for a sea-surface radiometer. First, the instrument must maintain radiometric stability under varying environmental conditions. Second, it has to be insensitive to the state of polarization of the incoming illumination. Third, it is necessary to ensure adequate sensitivity at the blue and red ends of the spectrum where the reflectance of coastal water is very low. Fourth, since sky conditions can change rapidly the spectral acquisition time should be minimized. Finally the spectral resolution has to be sufficient to resolve the red fluorescence signal generated by phytoplankton chlorophyll. In addition, practical requirements include the provision of a robust and waterproof housing, the desirability of controlling data acquisition remotely and the need to keep cables carrying low amplitude signals as short as possible. The photodetection system designed to meet these requirements was based on a thermoelectrically cooled CCD array coupled to a $0.125 \mathrm{~m}$ spectrograph (Oriel Instaspec IV) with a $0.2 \mathrm{~mm}$ wide input slit, giving a band pass of $4 \mathrm{~nm}$. Dual optical inputs to the spectrograph were provided by a bifurcated fibre bundle with a $3 \mathrm{~mm}$ diameter core, which served the dual purpose of simplifying the layout of the optical paths in the sensing head and randomizing the state of polarization of the incoming light. One end of the bundle terminated in a rectangular cross section which was imaged on the spectrograph input slit, while the other two ends received light from the collection optics. Since fibre optic input systems can suffer from variable bending losses, the bifurcated bundle was rigidly fixed inside the radiometer housing. The irradiance collector consisted of a PTFE disk $20 \mathrm{~mm}$ in diameter and $6 \mathrm{~mm}$ thick mounted in a blackened aluminium ring with a slightly relieved edge. The radiance collector consisted of a $75 \mathrm{~mm}$ focal length achromat with the fibre bundle end close to its rear focal plane, providing an acceptance half-angle of $1^{\circ}$. Light from the two collectors was presented sequentially to the spectrograph by means of solenoid-operated shutters whose blades obscured the fibre bundle ends. The magnitude of the radiance from the sea surface is much lower than the sky irradiance, and it is relatively deficient in red and blue wavelengths. To balance the two signals, the efficiency of the irradiance collector was adjusted by an appropriate choice of diffuser plate thickness and a blue glass filter (Schott BG14) was placed between the diffuser and the fibre bundle. A rotatable linear polarizer was placed in front of the radiance detector to allow the relative contribution of the horizontally plane polarized light reflected from the sea surface to be maximized or minimized (figure 1). The readout from the detector head was controlled by an interface card mounted on a standard computer motherboard enclosed in a waterproof deck

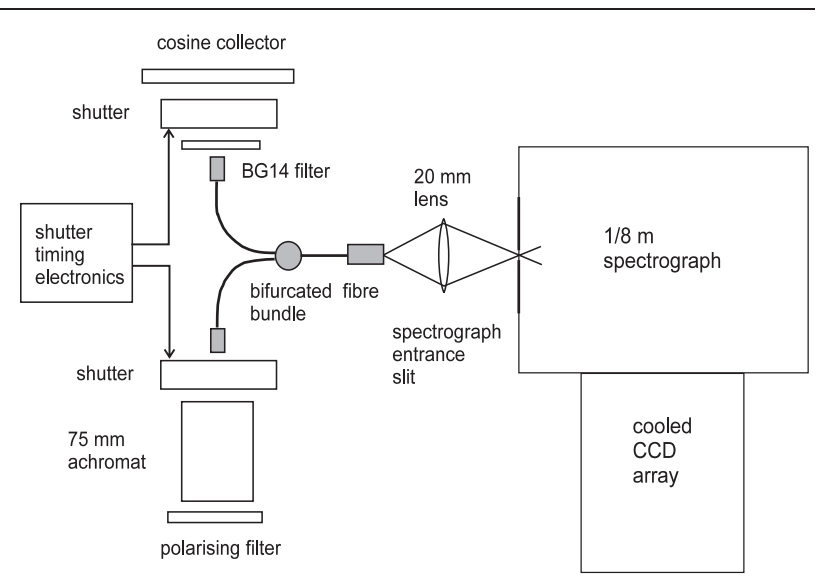

Figure 1. Optical layout of the sensing head.

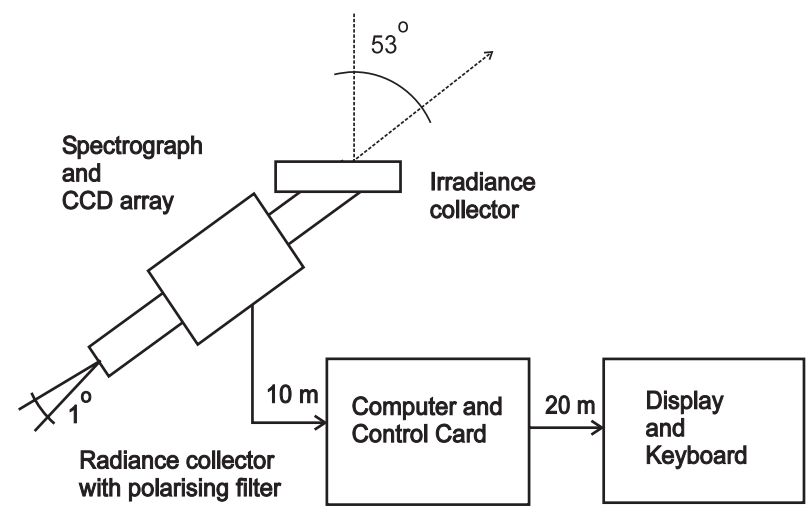

Figure 2. Mechanical arrangement for Brewster angle deployments.

box, and the head and deck box were connected by a $10 \mathrm{~m}$ cable. A second $10 \mathrm{~m}$ cable carried power, video and keyboard signals from the control console to the deck unit. The mechanical arrangement is shown schematically in figure 2 . The detector head was mounted $\approx 4 \mathrm{~m}$ above sea level and pointing forwards so as to view water that had not been disturbed by the ship. The area viewed at the sea surface was $\approx 0.2 \mathrm{~m}$ in diameter. During measurements the ship was steered at roughly right angles to the direct solar beam so as to avoid intense specular reflections and ship shadow.

\subsection{Calibration}

The accuracy of the spectrograph wavelength adjustment was regularly checked using lines from a low pressure mercury lamp, and was found to be very stable in spite of the high vibration levels experienced during measurements. Radiometric linearity of the detector/spectrograph combination was established by viewing a stabilized tungsten lamp source at a range of distances. The lamp output was monitored using a calibrated photodiode, and an excellent correlation $\left(r^{2}=0.99\right)$ was found for irradiances ranging from $50-900 \mathrm{~mW} \mathrm{~m}^{-2} \mathrm{~nm}^{-1}$. The cosine response of the diffusing plate on the irradiance sensor was measured by rotating the entire sensing head on a turntable in a collimated beam of white light. The response was within $2.5 \%$ of a true cosine for angles up to $65^{\circ}$ from normal incidence, falling to $10 \%$ at $85^{\circ}$ : this is close to the SeaWiFS specification for irradiance collectors. The field of 
view of the radiance optics was determined by tracking a point source at right angles to the optical axis. The absolute spectral response of the irradiance measurement was established by directly viewing a $1000 \mathrm{~W}$ standard lamp, and the response of the radiance measurement by viewing a Lambertian reflector (a $150 \mathrm{~mm} \times 150 \mathrm{~mm}$ Spectralon plate) illuminated by the same lamp. The effectiveness of the fibre bundle in rendering the detection system insensitive to the state of polarization of the incoming light was checked by placing a linear polarizer between a stable light source and the radiance detector and rotating the polarizer through $360^{\circ}$. Data were read from the CCD array and stored as ASCII files using Oriel proprietary software, and calibration factors to calculate radiance and irradiance spectra were applied using a spreadsheet. Overall, the instrument showed excellent stability in use. Periodic recalibrations using the standard lamp showed variations in sensitivity of $<5 \%$ during 12 months of deployment, including a longitudinal transect of the Atlantic Ocean.

\subsection{Recovery of water-leaving radiance}

If a perfectly smooth sea surface was viewed by a radiometer oriented at exactly $53^{\circ}$ to the vertical (the Brewster angle), reflected sky light could be eliminated using a vertically oriented polarizing filter. This approach was suggested by Gower (1980) for airborne radiometry and it has been used extensively by Fougnie et al (1999) for measurements from a pier. Unfortunately waves and diffuse sky light cause spectra measured through a vertical polarizer on a shipborne radiometer to contain a significant component derived from surface reflection. It is therefore necessary to estimate the contribution of this reflected light at all wavelengths so that it can be subtracted from the spectrum measured through the vertical polarizer. The semi-empirical procedure adopted involved several steps. First, the difference between measurements made with the polarizer oriented horizontally $\left(L_{\lambda}^{H}\right)$ and vertically $\left(L_{\lambda}^{V}\right)$ was used to determine the spectral distribution of reflected sky light. The water-leaving radiance at $750 \mathrm{~nm}$ was then assumed to be zero and a scaling factor $(F)$ was derived to estimate the magnitude of the sky light component passing through the vertical polarizer at this wavelength:

$$
F=L_{750}^{V} /\left(L_{750}^{H}-L_{750}^{V}\right) .
$$

It was assumed that this factor $F$ could be applied at all wavelengths to produce a scaled sky light spectrum which was subtracted from the signal measured through the vertical polarizer to recover the water-leaving radiance $\left(L_{\lambda}^{w}\right)$ :

$$
L_{\lambda}^{w}=L_{\lambda}^{V}-F\left(L_{\lambda}^{H}-L_{\lambda}^{V}\right), \quad \lambda=400-700 \mathrm{~nm} .
$$

The signal recovery procedure described above makes two key assumptions. First, that the water-leaving radiance is close to zero in the near-infrared, which is valid only for waters carrying a low burden of suspended sediment. Second, that the degree of linear polarization for water-leaving radiance at the angle of observation is negligible: this is intuitively reasonable for multiple scattering from a population of particles with a wide range of sizes, but needs further experimental investigation. Furthermore, the effect of waves and ship movement is to produce a strong modulation of the two signals as the

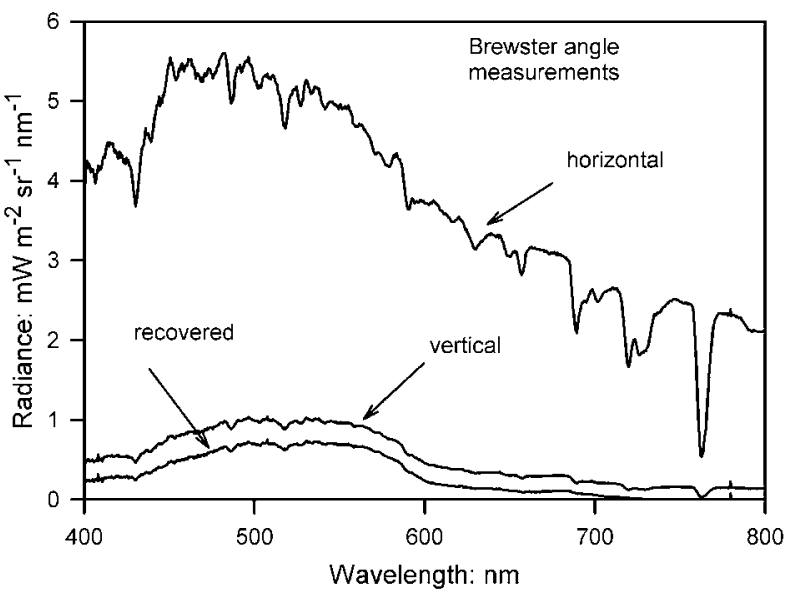

Figure 3. Recovery of sea-leaving radiance from two measurements of surface radiance through horizontal and vertical polarizing filters.

viewing angle changes. The data presented in this paper were therefore obtained by averaging over several wave periods, with acquisition times of the order of $10 \mathrm{~s}$. Data were only accepted if signals from the irradiance sensor remained constant during the acquisition sequence, but the technique is still likely to cause artefacts in conditions of broken cloud cover. The results of applying equations (1) and (2) to a typical Brewster angle radiance measurement are shown in figure 3. This figure also shows the appearance of Fraunhofer and atmospheric absorption lines in the $L_{\lambda}^{H}$ signal, indicating the high proportion of reflected sky light in radiance spectra measured directly from the surface (Kattawar and Xu 1992).

\section{Results}

Figure 4 shows a typical reflectance spectrum measured in Loch Linnhe in May 1997. The water column contained $1 \mathrm{mg} \mathrm{m}^{-3}$ of chlorophyll $a$ and the concentration of coloured dissolved organic matter (CDOM), measured as the absorption of a filtered sample at $440 \mathrm{~nm}$, was $0.2 \mathrm{~m}^{-1}$. It is possible to model the reflectance of the water column from a knowledge of the input irradiance and the concentrations of the optically significant components in the first optical depth using a numerical solution of the radiance transfer equation (Mobley 1994). The commercially available Hydrolight 4.0 program was used for this purpose, and the calculation incorporated the default absorption spectra and scattering functions for phytoplankton and CDOM provided with this program. These waters contain low concentrations of inorganic particles (determinations of total suspended particulate material were consistently below $1 \mathrm{mg} \mathrm{l}^{-1}$ ), and so the optical effects of suspended sediment were assumed to be negligible. The results for surface water with the composition measured at the Loch Linnhe station are plotted in figure 4, which indicates that the retrieved reflectance spectra are at least consistent with the modelled values. Figure 4 also shows a solar-stimulated chlorophyll fluorescence peak, centred on $685 \mathrm{~nm}$, is just visible above the background at surface concentrations of $1 \mathrm{mg} \mathrm{m}^{-3}$. This supports the suggestion that fluorescence may provide a useful key to interpreting remotely sensed reflectance when data from new hyperspectral satellite 


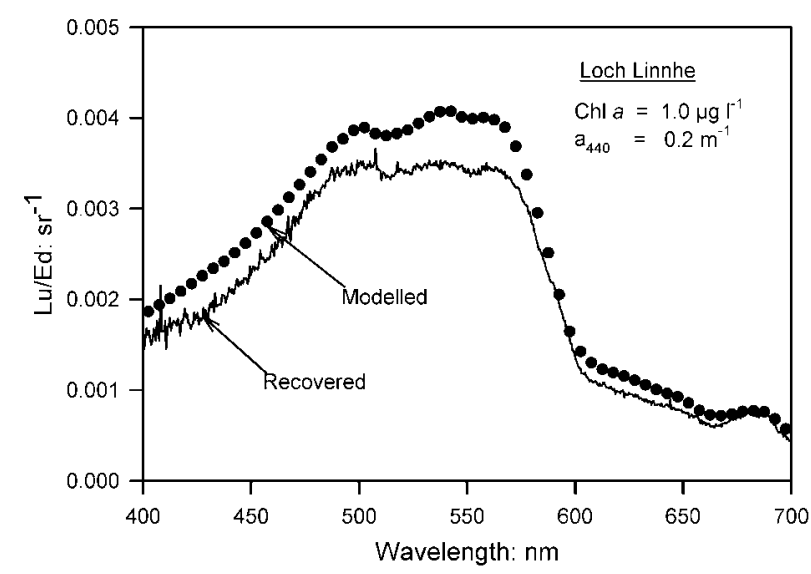

Figure 4. Comparison of reflectance measured using the procedure illustrated in figure 3 with the output of a radiance transfer model of a typical sea loch water column.

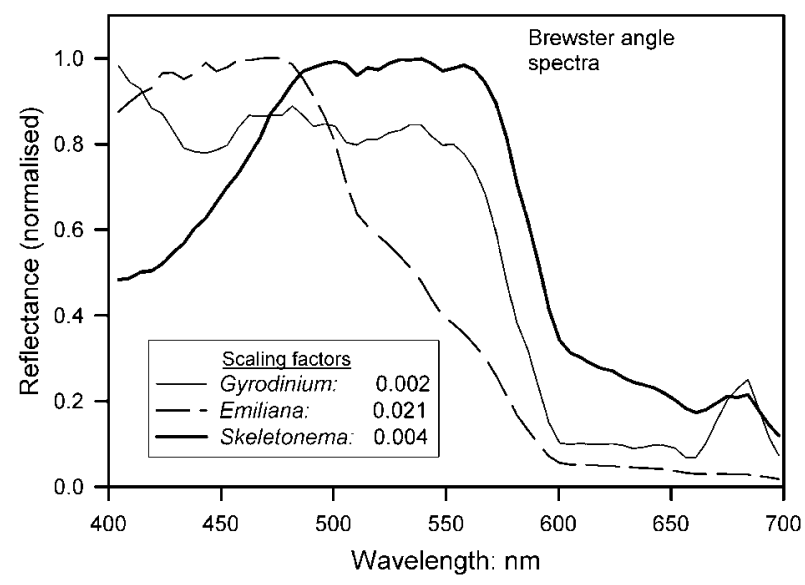

Figure 5. Reflectance spectra for blooms of three different phytoplankton species: Emiliania huxleyi (English Channel), Gyrodinium sp. (English Channel) and Skeletonema costatum (Loch Linnhe).

radiometers becomes available (Babin et al 1996, Letelier and Abbott 1996).

Figure 5 shows recovered reflectance curves for three stations where phytoplankton blooms were found, two in the English Channel in August 1997 and one in Loch Linnhe in May 1997. Microscopic inspection of water samples indicated that the blooms were dominated by single species: Emiliania huxleyi and Gyrodinium (species unknown) in the English Channel and Skeletonema costatum in Loch Linnhe. There were undoubtedly other optically significant materials in the water column, particularly gelbstoff in Loch Linnhe. The plots in figure 5 have been normalized to emphasize differences in spectral shape, but the peak values (inset) indicate that the reflectance from $E$. huxleyi was significantly greater than from the other two species.

\section{Discussion}

Spectroradiometric measurements made from ships at the Brewster angle lack the synoptic view which can be obtained from satellite images, and are sensitive to degradation from reflected sky light and the inherent instability of the observing platform. However, the trials described here indicate that valuable optical information can still be retrieved. It is possible to carry out one-dimensional transects at high spatial resolution and provide information on sub-pixel optical variability which complements satellite imagery. Surveys can be carried out in conditions when airborne imagery is not available due to operational restrictions or heavy cloud cover, which is a major advantage for monitoring the distribution of plumes of contaminants derived from land sources or ships. It is possible to operate in areas where aircraft access is restricted and satellite radiometry is degraded by the presence of adjacent highly reflective land pixels. In principle, reflectance measurements in coastal waters can provide information on shallow-water bathymetry (Lee et al 1998), sediment transport (Moore et al 1999), the formation on nuisance algal blooms and surface scums and the interaction of river plumes with coastal topography. In practice, however, it is necessary to orientate the reflectance sensor to minimize sun glint and to accept the fact that the effective recovery of waterleaving radiance spectra relies on semi-empirical corrections for surface-reflected sky light. These corrections can be carried out by the subtraction of an empirically determined proportion of sky radiance or irradiance or by the method of polarization discrimination described in this paper. Both techniques rely on the assumption of zero water-leaving radiance at $750 \mathrm{~nm}$, and neither is likely to prove accurate in very turbid waters or in the presence of surface scums and films. However these conditions are likely to generate reflectance spectra which are sufficiently distinctive for monitoring purposes, even if quantitative radiometric correction is not feasible. Given further development, near-surface spectral measurements may find a cost-effective role in coastal surveys and water quality assessment.

\section{Acknowledgments}

Funding was provided by the UK Natural Environment Council in the form of studentships for PW and DMK and a research grant from the SeaWiFS Exploitation Initiative. Friends and colleagues at Dunstaffnage Marine Laboratory and Plymouth Marine Laboratory provided ship time and calibration facilities for which we are extremely grateful.

\section{References}

Babin M, Morel A and Gentili B 1996 Remote sensing of sea surface sun-induced chlorophyll fluorescence: consequences of natural variations in the optical characteristics of phytoplankton and the quantum yield of chlorophyll $a$ fluorescence Int. J. Remote Sens. 17 2417-48

Bukata R P 1995 Optical Properties and Remote Sensing of Inland and Coastal Waters (Boca Raton, FL: CRC Press) p 384

Cunningham A, Wood P and Jones K 2001 Reflectance properties of hydrographically and optically stratified fjords (Scottish sea lochs) during the spring diatom bloom Int. J. Remote Sens. 22 2885-97

Fougnie B, Frouin R, Lecomte P and Deschampes P 1999 Reduction of skylight reflection effects in the above-water measurement of diffuse marine reflectance Appl. Opt. 38 3844-56

Gower J F R 1980 Observations of in situ fluorescence of chlorophyll $a$ in Saanich Inlet Bound. Layer Meteorol. 18 $235-45$ 
Kattawar G W and Xu X 1992 Filling in of Fraunhofer lines in the ocean by Raman scattering Appl. Opt. 31 6491-500

Lee Z P, Carder K L, Mobley C D, Steward R G and Patch J S 1998 Hyperspectral remote sensing for shallow waters I: a semianalytical model Appl. Opt. 37 6329-38

Letelier R M and Abbott M R 1996 An analysis of chlorophyll fluorescence algorithms for the moderate resolution imaging spectrometer (MODIS) Remote Sens. Environ. 58 215-23

Mobley C D 1994 Light and Water (San Diego, CA: Academic) p 592

Moore G F, Aiken J and Lavender S J 1999 The atmospheric correction of water colour and the quantitative retrieval of suspended particulate matter in case II waters: application to MERIS Int. J. Remote Sens. 20 1713-33

Mueller J L and Austin R W 1995 Ocean Optics Protocols for SeaWiFS Validation, Revision 1, NASA Tech. Memo. 104566, vol 25, ed S B Hooker, E R Firestone and J G Acker (Greenbelt, MD: NASA Goddard Space Flight Center)

Wood P and Cunningham A 2001 Ship-borne measurements of ocean colour: development of a CCD-based reflectance radiometer and trials on a longitudinal transect of the Atlantic ocean Int. J. Remote Sens. 22 99-111 